Philadelphia College of Osteopathic Medicine DigitalCommons@PCOM

PCOM Scholarly Papers

$7-1-2014$

\title{
Web-Based Objective Structured Clinical Examination with Remote Standardized Patients and Skype: Resident Experience
}

Erik E. Langenau

Philadelphia College of Osteopathic Medicine, erikla@pcom.edu

Elizabeth Kachur

Dot Horber

Follow this and additional works at: http://digitalcommons.pcom.edu/scholarly_papers

Part of the Health and Medical Administration Commons, Health Information Technology Commons, and the Medical Education Commons

\section{Recommended Citation}

Langenau, Erik E.; Kachur, Elizabeth; and Horber, Dot, "Web-Based Objective Structured Clinical Examination with Remote Standardized Patients and Skype: Resident Experience" (2014). PCOM Scholarly Papers. Paper 240.

http://digitalcommons.pcom.edu/scholarly_papers/240 
Medical Education

\title{
Web-based objective structured clinical examination with remote standardized patients and Skype: Resident experience
}

\author{
Erik Langenau ${ }^{\mathrm{a}, *}$, Elizabeth Kachur ${ }^{\mathrm{b}}$, Dot Horber $^{\mathrm{c}}$ \\ ${ }^{a}$ National Board of Osteopathic Medical Examiners, Philadelphia College of Osteopathic Medicine, Department of Family Medicine, Philadelphia, USA \\ ${ }^{\mathrm{b}}$ National Board of Osteopathic Medical Examiners, USA \\ c Continuous Professional Development and Innovations, National Board of Osteopathic Medical Examiners, USA
}

\section{A R T I C L E I N F O}

\section{Article history:}

Received 4 January 2014

Received in revised form 5 April 2014

Accepted 28 April 2014

\section{Keywords:}

Web-based objective structured clinical

examination

Communication

Formative assessment

e-Learning

Remote standardized patients

Online learning

Synchronous distance learning

\begin{abstract}
A B S T R A C T
Objective: Using Skype and remote standardized patients (RSPs), investigators sought to evaluate user acceptance of a web-based objective structured clinical examination (OSCE) among resident physicians. Methods: After participating in four web-based clinical encounters addressing pain with RSPs, 59 residents from different training programs, disciplines and geographic locations completed a 52-item questionnaire regarding their experience with Skype and RSPs. Open-ended responses were solicited as well.

Results: The majority of participants (97\%) agreed or strongly agreed the web-based format was convenient and a practical learning exercise, and $90 \%$ agreed or strongly agreed the format was effective in teaching communication skills. Although 93\% agreed or strongly agreed they could communicate easily with RSPs using Skype, $80 \%$ preferred traditional face-to-face clinical encounters, and $58 \%$ reported technical difficulties during the encounters. Open-ended written responses supported survey results. Conclusion: Findings from this study expose challenges with technology and human factors, but positive experiences support the continued investigation of web-based OSCEs as a synchronous e-learning initiative for teaching and assessing doctor-patient communication. Such educational programs are valuable but unlikely to replace face-to-face encounters with patients.

Practice implications: This web-based OSCE program provides physician learners with additional opportunity to improve doctor-patient communication.
\end{abstract}

(c) 2014 Elsevier Ireland Ltd. All rights reserved.

\section{Introduction}

Recent educational initiatives have expanded the scope of competency assessment of physicians to address the domains endorsed by the Accreditation Council on Graduate Medical Education (ACGME) and the American Osteopathic Association (AOA) [1,2]. Numerous studies have cited the importance of teaching and assessing competencies other than medical knowledge. In particular, doctor-patient communication skills have been identified as critical for physician work [3,4]. Consequently educational programs have expanded beyond the classroom to include real patients, standardized patients (SPs) and objective

\footnotetext{
* Corresponding author at: Philadelphia College of Osteopathic Medicine, Department of Family Medicine, 4190 City Avenue, Suite 216, Rowland Hall, Philadelphia, PA 19131, USA.

Tel.: +1 215871 6688; fax: +1 2158716395 .

E-mail addresses: erikla@pcom.edu (E. Langenau), mededdev@earthlink.net (E. Kachur), dhorber@nbome.org (D. Horber).
}

structured clinical examinations (OSCEs) [5]. Unlike medical school training programs where SP-based programs are frequently utilized, only $12.3 \%$ of residency training programs utilize SP examinations, and only $14 \%$ utilize OSCEs [6]. SP-based examinations and OSCEs provide opportunities to evaluate doctor-patient communication skills, but they are costly and typically require face-to-face interaction, which may be prohibitive for residents and physicians who are geographically distributed across training sites.

Two pedagogical strategies have been used to overcome the challenge of teaching doctor-patient communication to medical students and residents at different geographic locations: asynchronous web-based learning modules and synchronous web-based OSCEs. For instance, The American Academy of Communication in Healthcare developed Doc.com, a web-based resource to assist in teaching communication skills with the use of asynchronous multimedia instruction [7]. Two studies have shown this program to be effective in teaching communication to internal medicine residents who completed the modules online 
[7.8]. On the other hand, synchronous web-based OSCEs have a number of advantages over other online educational programs with regard to teaching communication skills; they are interactive and address clinical skills in addition to medical knowledge. Two studies, limited to one institution and one proprietary software program, have shown web-based OSCEs to be valuable and well received by learners [8.9].

Few research studies have investigated the use of remote standardized patients (RSPs) who communicate with physicians via the internet rather than in person [8,9], and to our knowledge, no studies have investigated the use of RSPs with residents from multiple-training institutions with Skype. As a pilot, the National Board of Osteopathic Medical Examiners (NBOME) developed a formative four-station web-based OSCE using Skype and RSPs for physicians in residency training programs. Each of the four cases required residents to investigate issues related to pain and pain management, addressing an educational need for physicians to enhance their ability to treat pain in a responsible manner [10]. The web-based OSCE program was designed to increase educational opportunities for residents and practicing physicians by developing a web-based formative assessment of doctor-patient communication that is relevant, practical, and authentic. The purpose of the study is to evaluate the user experience and acceptance by analyzing survey responses from participating resident physicians.

\section{Methods}

Resident physicians participated in a web-based communication exercise with RSPs using Skype. Each resident participated in four 30-min online clinical encounters related to pain assessment and counseling. Opinions regarding the program's format, technologies, cases, assessment methods, and feedback were collected in the web-delivered physician post-exercise survey.

\subsection{Sample}

Using NBOME's email database of examinees, an email invitation to participate was sent to all of those who successfully completed the Comprehensive Osteopathic Medical Licensing Examination Level 2-Performance Evaluation (COMLEX-USA Level 2-PE) and Level 2-Cognitive Evaluation (COMLEX-USA Level 2-CE) (therefore meeting graduation requirements) in the 2011-2012 ( $n=5004), 2010-2011 \quad(n=4757), 2009-2010 \quad(n=4061)$, and 2008-2009 $(n=4698)$ testing cycles. Invited study participants were instructed they would receive a $\$ 100$ gift card and opportunity to participate in novel learning activity using Skype and RSPs. Among the invited respondents who completed the demographic survey within the first $48 \mathrm{~h}$ (412 residents), 60 were randomly selected to participate. Only physicians enrolled in residency training programs were selected for the study. Only one resident failed to complete the study. Because the invitation to participate was distributed to all eligible osteopathic resident physicians in the United States, the final sample of 59 included osteopathic physicians who varied in age, gender, ethnicity, school of graduation, location of current training and discipline. One participant reporting being less than 25 years of age and one being more than 50 years of age, while the majority (59.3\%) gave their age as 29 years or younger. The sample included 56\% women and $44 \%$ men. Participating residents reported being in residency or fellowship programs from 23 different states and reported graduating from 22 different colleges of osteopathic medicine (Table 1).

\subsection{Web-based OSCE}

Over the 8-week testing period (October to December 2012), 59 resident physicians completed 236 web-based clinical encounters.
Table 1

Distribution of race and ethnicity, training level and area of specialty for participant sample $(n=59)$.

\begin{tabular}{lc}
\hline Demographic & Total (\%) \\
\hline Race/ethnicity & \\
Hispanic & $3(5.1 \%)$ \\
Asian & $9(15.3 \%)$ \\
African American & $4(6.8 \%)$ \\
Caucasian & $42(71.2 \%)$ \\
More than one race & $1(1.7 \%)$ \\
Total & $59(100 \%)$ \\
Training level & \\
Intern/resident (1st year) & \\
Resident (2nd year) & $16(27.1 \%)$ \\
Resident (3rd year) & $24(40.7 \%)$ \\
Resident (4th year) & $14(23.7 \%)$ \\
Fellow & $4(6.8 \%)$ \\
Total & $1(1.7 \%)$ \\
Primary specialty & $59(100 \%)$ \\
Emergency medicine & \\
Family medicine & \\
Internal medicine & $5(8.5 \%)$ \\
OB/GYN & $16(27.1 \%)$ \\
Pediatrics & $12(20.3 \%)$ \\
Surgery & $6(10.2 \%)$ \\
Other & \\
Total & $5(8.5 \%)$ \\
a & $1(1.7 \%)$ \\
Resing & $14(23.7 \%)$ \\
& $59(100 \%)$ \\
\hline
\end{tabular}

a Responses to "Other" included the following: anesthesiology, internal medicine-pediatrics, neurological surgery, ophthalmology, orthopedic surgery, pathology, physical medicine and rehabilitation, psychiatry (5) and traditional rotating internship (2).

Encounters were scheduled at the convenience of the residents between the hours of 7:00 AM ET and 1:00 AM ET, allowing for daytime and evening participation in all time zones across the United States. Most encounters were conducted during weekday evening hours. All were conducted using Skype, with each RSP conducting the encounter from his or her home (Fig. 1).

Each resident participated in four encounters, starting with a 15min doctor-patient communication task regarding the assessment and counseling of the patient's pain. Subsequently, there was a 5-min silent period when the RSP completed the pertinent rating forms, and the resident engaged in a self-assessment, completing a global assessment. The encounter ended with a 10-min debriefing session, which was led by the RSP. For each encounter, the RSP completed a global assessment form and key action checklist; the physician completed a self-assessment global rating form. The day following the encounter, each resident received the completed global assessment, key action checklist and self-assessment forms along with teaching points specific to the encounter. Written assessments were meant to enhance the learning experience by augmenting the verbal feedback received immediately after the encounter.

Content for the four doctor-patient communication clinical encounters was created by a 12-person case development workgroup comprised of medical education experts, standardized patient trainers, standardized patients, and physicians familiar with pain management. All had expertise in clinical skills testing, case development and psychometrics. Content was created, reviewed and endorsed for the following four clinical scenarios with each case addressing elements of pain and pain management, applicable to physicians across disciplines.

1. 35 year old woman with 3 months of headache after a motor vehicle accident and neck soft tissue injury (referred pain).

2. 48 year old woman with 4 weeks of left sided chest pain (noncardiac).

3. 45 year old man with long standing intermittent low back pain (opioid use/abuse). 


\section{Remote Standardized Patient (RSP)}

\section{Physician \\ Learner}

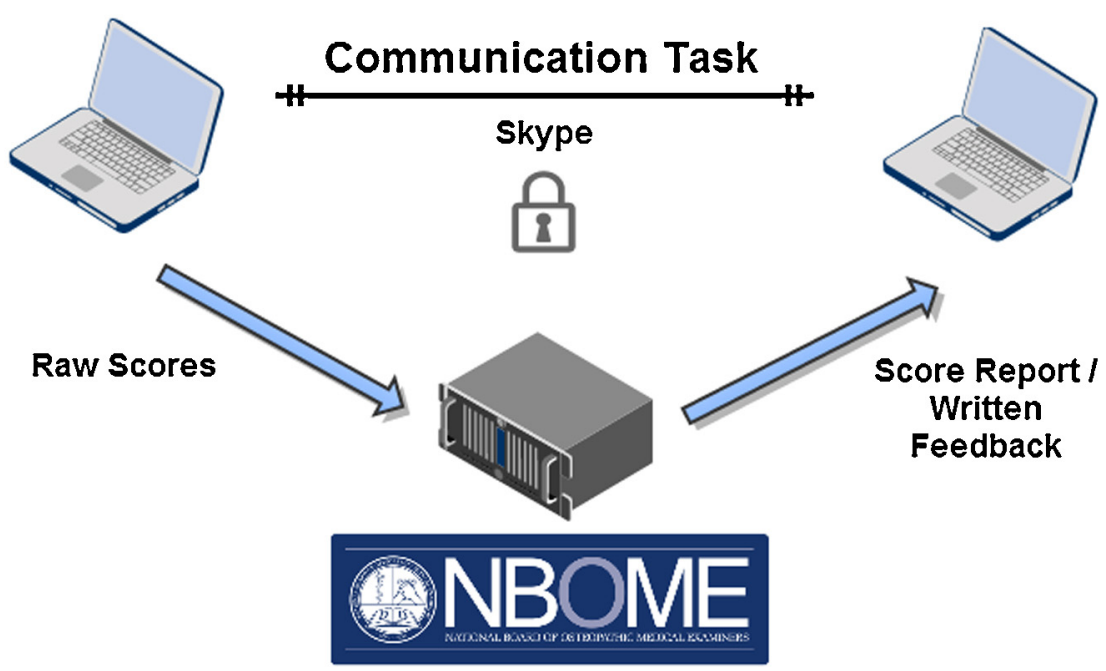

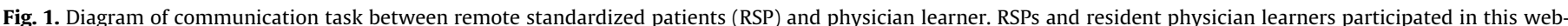

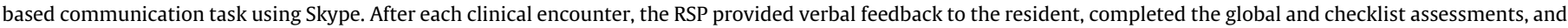
forwarded them to the NBOME for processing. The following day, assessments and teaching points were returned by email to each resident participant.

4. 18 year old man with 2 weeks of shoulder pain while pitching (overuse injury).

Case development included role playing, portrayal critique, and RSP training material modification. The committee also created a 12-14 item case-specific key action checklists for each case. Checklists (with elements identified as done or not done) were created by expert consensus by members of the Case Development Committee. The number of checklist items varied between 12 and 14 items for each case, depending on the specific nature of the pain complaint. Items included a combination of important elements to elicit during the history: location, palliation, provocation, quality, radiation, severity, associated symptoms, timing, past medical history, impact on daily living, diagnosis, prognosis, alternative treatments, recent trauma, opioid use, and social history.

Informed by a variety of valid communication assessments such as the Kalamazoo Essential Elements Communication Checklist (Adapted) [11], a global communication assessment was developed and reviewed by the case development workgroup. Slight modifications were made to the scale, rubric and instructions to make the global assessment relevant for a web-based encounter. This final instrument was also reviewed and endorsed by NBOME's Clinical Skills Testing Advisory Committee, another group of medical experts in clinical skills assessment. The final assessment was used as both the global communication assessment, as well as the self-assessment. The instrument included eight different global measures: builds a relationship, opens the discussion, gathers information, understands the patient's perspective, shares information, reaches agreement, provides closure, and overall patient satisfaction. Each of these global measures was scored using a fourpoint Likert-type scale: needs much improvement (1), needs some improvement (2), done adequately (3), and done excellently (4).

Four standard "Teaching Points" documents, specific for each case, were developed by NBOME staff clinicians and reviewed by members of the Case Development Committee. The document was shared with residents after completing each encounter. Each document included information regarding recommendations for obtaining a thorough pain history (onset, duration, quality, etc.), recommendations for incorporating the use of OMT into treatment recommendations, and details specific to each condition (costochondritis, tension headache, shoulder overuse injury and opioid use/abuse).

All cases and corresponding assessments were pilot tested by NBOME staff clinicians and the RSPs who participated in the study. All nine RSPs were experienced SPs and received 4-6 h of training for their case. Training was also conducted using Skype. Four RSPs were from California, four were from New York, and one was from Pennsylvania.

\subsection{Physician post-exercise questionnaire}

The physician post-exercise survey was used to collect data from each resident after all four doctor-patient encounters were completed. Questionnaire development incorporated recommendations from NBOME's 10-member Continuous Fitness for Practice Task Force comprised of experts in medical education, clinical practice, and psychometrics. The physician post-exercise survey was delivered online using Survey Monkey.

The survey instrument consisted of 52 Likert-type items arranged in 10 sections with opportunity to provide open-ended comments for each section, as well as a 14 -item adjective checklist [12]. The 10 sections included questions regarding general format, technology, scheduling, RSP experience, believability of cases, verbal feedback, global assessment, checklist assessment, teaching points, and overall experience. In conjunction with pilot testing the cases with the trained RSPs before the study, four clinicians pilot tested the online survey and made minor modifications to the format.

\subsection{Analysis}

Data from the demographic and post-exercise surveys were extracted from Survey Monkey using MS Office Excel and analyzed using the IBM SPSS Statistics program, version 21. For both instruments, analysis consisted of descriptive statistics, primarily frequency counts and percentages. Each participating RSP and resident completed a consent form prior to project commencement, and Institutional Review Board (IRB) approval was granted 
Table 2

Responses to physician post-exercise survey $(n=59)$.

\begin{tabular}{|c|c|c|c|c|c|}
\hline & Strongly disagree & Disagree & Agree & Strongly agree & $\mathrm{N} / \mathrm{A}$ \\
\hline \multicolumn{6}{|l|}{ General } \\
\hline The web-based format was convenient for me & 1 & 1 & 29 & 28 & 0 \\
\hline This was a practical learning experience & 1 & 1 & 29 & 28 & 0 \\
\hline $\begin{array}{l}\text { The web-based format was effective in } \\
\text { teaching me communication skills }\end{array}$ & 0 & 6 & 30 & 23 & 0 \\
\hline \multicolumn{6}{|l|}{ Technology } \\
\hline $\begin{array}{l}\text { I am familiar with Skype (e.g., I have used Skype } \\
\text { before this exercise) }\end{array}$ & 5 & 8 & 22 & 24 & 0 \\
\hline $\begin{array}{l}\text { I am familiar with other video conferencing } \\
\text { programs (similar to Skype) }\end{array}$ & 6 & 19 & 18 & 14 & 2 \\
\hline I found Skype easy to use & 0 & 1 & 25 & 33 & 0 \\
\hline $\begin{array}{l}\text { I found the Technology Instructions For Physicians } \\
\text { document useful for completing the exercise }\end{array}$ & 0 & 1 & 28 & 23 & 7 \\
\hline $\begin{array}{l}\text { I found the "Technology Check" (call in hours) with } \\
\text { the NBOME helpful }\end{array}$ & 0 & 1 & 10 & 12 & 36 \\
\hline $\begin{array}{l}\text { I found the NBOME staff helpful when addressing } \\
\text { technology-related issues }\end{array}$ & 0 & 2 & 9 & 11 & 37 \\
\hline $\begin{array}{l}\text { I did not experience any technical difficulties during } \\
\text { the encounters }\end{array}$ & 11 & 23 & 15 & 8 & 2 \\
\hline \multicolumn{6}{|l|}{ Scheduling } \\
\hline Scheduling encounters was easy & 0 & 2 & 25 & 32 & 0 \\
\hline $\begin{array}{l}\text { Email was an effective communication tool for scheduling } \\
\text { the encounter }\end{array}$ & 0 & 1 & 20 & 38 & 0 \\
\hline Staff members responsible for scheduling were professional & 0 & 0 & 12 & 47 & 0 \\
\hline \multicolumn{6}{|l|}{ Remote standardized patient experience } \\
\hline $\begin{array}{l}\text { I was able to communicate easily with the remote } \\
\text { standardized patients (RSPs) }\end{array}$ & 0 & 4 & 39 & 16 & 0 \\
\hline $\begin{array}{l}\text { I was able to get the information I needed from the remote } \\
\text { standardized patients (RSPs) }\end{array}$ & 0 & 4 & 35 & 20 & 0 \\
\hline $\begin{array}{l}\text { Exercises increased my awareness of addressing patients' } \\
\text { concerns related to pain }\end{array}$ & 1 & 10 & 29 & 19 & 0 \\
\hline Exercises increased my ability to elicit a comprehensive pain history & 1 & 8 & 35 & 15 & 0 \\
\hline $\begin{array}{l}\text { Exercises increased my comfort in eliciting a comprehensive } \\
\text { pain history from patients }\end{array}$ & 1 & 7 & 36 & 14 & 1 \\
\hline Exercises increased my ability to counsel patients about & 1 & 6 & 40 & 11 & 1 \\
\hline pain-related issues and treatment & & & & & \\
\hline $\begin{array}{l}\text { Exercises increased my comfort in counseling patients about } \\
\text { pain-related issues and treatment }\end{array}$ & 1 & 5 & 42 & 11 & 0 \\
\hline $\begin{array}{l}\text { I felt confident in my ability to describe osteopathic manipulative } \\
\text { treatment (OMT) as a management option for reducing pain }\end{array}$ & 0 & 12 & 28 & 15 & 4 \\
\hline Remote standardized patients (RSPs) were professional & 0 & 0 & 22 & 37 & 0 \\
\hline \multicolumn{6}{|l|}{ Believability of case } \\
\hline The portrayal of the chest pain case was believable & 0 & 1 & 34 & 24 & 0 \\
\hline The portrayal of the headache case was believable & 0 & 1 & 32 & 26 & 0 \\
\hline The portrayal of the low back pain case was believable & 0 & 0 & 29 & 30 & 0 \\
\hline The portrayal of the shoulder pain case was believable & 1 & 5 & 31 & 22 & 0 \\
\hline \multicolumn{6}{|l|}{ Verbal feedback } \\
\hline $\begin{array}{l}\text { The overall format for receiving verbal feedback (from the remote } \\
\text { standardized patient) was valuable }\end{array}$ & 0 & 1 & 32 & 26 & 0 \\
\hline The verbal feedback I received from the chest pain case was valuable & 1 & 1 & 30 & 27 & 0 \\
\hline The verbal feedback I received from the headache case was valuable & 0 & 4 & 33 & 22 & 0 \\
\hline The verbal feedback I received from the low back pain case was valuable & 0 & 2 & 31 & 26 & 0 \\
\hline The verbal feedback I received from the shoulder pain case was valuable & 1 & 6 & 28 & 24 & 0 \\
\hline \multicolumn{6}{|l|}{ Written assessment (global assessment) } \\
\hline The process of completing the self-assessment forms was valuable. & 1 & 11 & 39 & 8 & 0 \\
\hline $\begin{array}{l}\text { Information provided in the global communication assessment } \\
\text { (completed by the RSP) was valuable }\end{array}$ & 0 & 1 & 37 & 21 & 0 \\
\hline $\begin{array}{l}\text { Information provided in the global communication assessment } \\
\text { (completed by the RSP) was an accurate assessment of my } \\
\text { performance during the exercise }\end{array}$ & 0 & 3 & 42 & 14 & 0 \\
\hline \multicolumn{6}{|l|}{ Written assessment (checklist) } \\
\hline Information provided in the chest pain checklist was valuable & 0 & 3 & 40 & 16 & 0 \\
\hline $\begin{array}{l}\text { Information provided in the chest pain checklist was an accurate } \\
\text { assessment of my performance during the encounter }\end{array}$ & 0 & 3 & 41 & 15 & 0 \\
\hline Information provided in the headache checklist was valuable & 0 & 3 & 42 & 14 & 0 \\
\hline $\begin{array}{l}\text { Information provided in the headache checklist was an accurate } \\
\text { assessment of my performance during the encounter }\end{array}$ & 0 & 5 & 42 & 12 & 0 \\
\hline Information provided in the low back pain checklist was valuable & 0 & 2 & 42 & 15 & 0 \\
\hline
\end{tabular}




\begin{tabular}{|c|c|c|c|c|c|}
\hline & Strongly disagree & Disagree & Agree & Strongly agree & $\mathrm{N} / \mathrm{A}$ \\
\hline $\begin{array}{l}\text { Information provided in the low back pain checklist was an } \\
\text { accurate assessment of my performance during the encounter }\end{array}$ & 0 & 4 & 41 & 14 & 0 \\
\hline Information provided in the shoulder pain checklist was valuable & 0 & 2 & 41 & 16 & 0 \\
\hline $\begin{array}{l}\text { Information provided in the shoulder pain checklist was } \\
\text { an accurate assessment of my performance during the encounter }\end{array}$ & 1 & 3 & 42 & 13 & 0 \\
\hline \multicolumn{6}{|l|}{ Teaching point } \\
\hline The chest pain teaching points were valuable & 0 & 5 & 35 & 19 & 0 \\
\hline The headache teaching points were valuable & 0 & 4 & 36 & 19 & 0 \\
\hline The low back pain teaching points were valuable & 0 & 5 & 35 & 19 & 0 \\
\hline The shoulder pain teaching points were valuable & 0 & 7 & 33 & 19 & 0 \\
\hline \multicolumn{6}{|l|}{ Overall experience } \\
\hline I prefer this web-based format to traditional face-to-face clinical exercises & 19 & 28 & 9 & 3 & 0 \\
\hline The amount of work required for this exercise was appropriate & 0 & 1 & 46 & 12 & 0 \\
\hline $\begin{array}{l}\text { As a result of this exercise, I feel more confident in my ability to } \\
\text { communicate with my patients with regard to pain }\end{array}$ & 3 & 7 & 37 & 10 & 2 \\
\hline I would recommend this communication exercise to my colleagues & 2 & 7 & 34 & 14 & 2 \\
\hline I would register for another web-based exercise like this in the future & 2 & 3 & 33 & 19 & 2 \\
\hline I was satisfied with the overall experience (web-based exercise) & 1 & 2 & 33 & 22 & 1 \\
\hline
\end{tabular}

by the Center for the Advancement of Healthcare Education and Delivery (C-AHEAD) for conducting the study.

\section{Results}

All 59 residents completed the 52-item questionnaire. A summary of responses can be found in Table 2 .

As demonstrated in Table 2, responses to questions regarding the overall format of the study were very positive, indicated by that 97\% agreed or strongly agreed the web-based format was convenient and a practical learning exercise. Ninety percent agreed or strongly agreed the web-based format was effective in teaching communication skills. Additional written comments regarding the general approach included the following: two respondents stated the task was more challenging than in person, another acknowledged the task required modification of communication style, and another identified challenges with technology.

Regarding the technologies used in the study, results were somewhat mixed. Of participants, $97 \%$ agreed or strongly agreed to the statement "Skype was easy to use." However, 57\% had technical difficulties as indicated by responding disagree or strongly disagree to the statement "I did not experience any technical difficulties during the encounters." A number of written responses highlighted frustrations with connectivity (2), as well as audio (5) and video (3) quality.

All agreed or strongly agreed RSPs were professional, and 93\% agreed or strongly agreed residents could communicate easily with the RSPs. Many residents reported an improved ability to elicit a pain history and to counsel patients regarding treatment for pain at the conclusion of the study. Eighty-five percent of the participants agreed or strongly agreed that the study's exercises increased their ability not only to elicit a comprehensive pain history from patients, but also their comfort in doing so. Similarly, 86\% agreed or strongly agreed the exercises increased their ability to counsel patients about pain-related issues and treatment, and 90\% reported an increased comfort in providing counseling. In addition, as osteopathic physicians, 73\% agreed or strongly agreed they felt confident in their ability to describe Osteopathic Manipulative Treatment as a management option for reducing pain. Despite supportive responses, some written comments exposed challenges: "it was difficult to be empathetic through video conference" and "I felt like there was a disconnection." Written responses exposed challenges with establishing rapport with RSPs (1), conveying empathy (1), limited comparability with live encounters
(1), and inability to solicit history during physical examination (1). Two respondents provided additional written documentation supporting the value of using such encounters, especially in the context of teaching how to obtain a pain history.

Feedback was an important component of the exercise. Nearly all participants (97\%) agreed or strongly agreed the overall format for receiving verbal feedback from the RSPs was valuable. One comment addressed the value of immediate feedback by stating "Immediate feedback was very effective." Written feedback, through global and checklist assessments, were also valued.

For instance, $98 \%$ agreed or strongly agreed the information provided in the global communication assessment completed by the RSP was valuable, and $80 \%$ agreed or strongly agreed completing the self-assessment was valuable. Regarding verbal feedback provided by RSPs, written comments emphasized the value of receiving immediate verbal feedback (2), identified discrepancies between written feedback and verbal feedback provided by the RSP (1), and identified discrepancies between anecdotal verbal feedback from "real patients" and verbal feedback provided by the RSP (1). Regarding written feedback in the form of checklists and global assessments, written comments identified the value in the global assessment, especially when compared to the self-assessment (2), disagreement of information contained within the global assessment (2), and disagreement of information contained within the checklists (2). In general, survey findings were supported by written comments such as "I think filling out the global self-assessment seemed odd at first, but it was good to compare it to how the patient thought I did."

In support for the web-based format, $88 \%$ agreed or strongly agreed to the statement "I would register for another web-based exercise like this in the future," and the vast majority (93\%) agreed or strongly agreed they were "satisfied with the overall experience." Among participants, 80\% agreed or strongly agreed they felt more comfortable with their ability to communicate with patients regarding pain. Although survey responses were generally positive, most preferred face-to-face instruction over this format, as indicated by $80 \%$ disagreeing or strongly disagreeing to the statement "I prefer this web-based format to traditional face-toface clinical exercises." Regarding the overall experience, written responses identified poor comparability with face-to-face encounters (9), general dislike for OSCEs (2), challenges of communicating without the ability to perform a physical examination (2), and general technical challenges (2). Additional written responses identified the web-based OSCE as a good 
Descriptors used by Residents, $n=59$

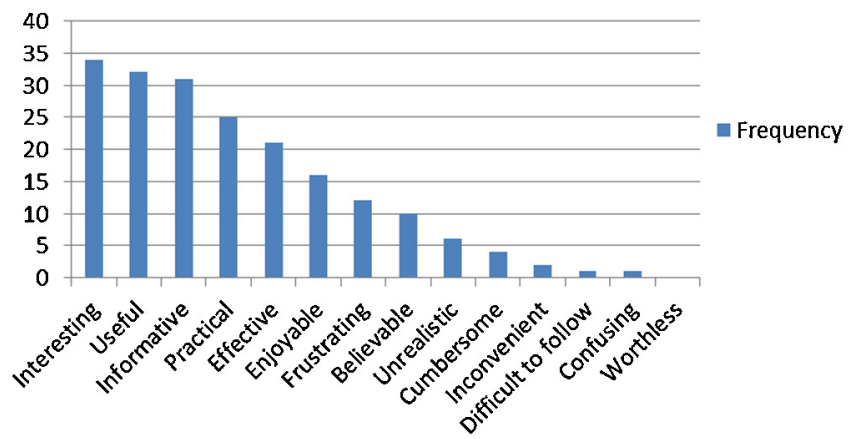

Fig. 2. Descriptors used by participant sample to describe the study $(n=59)$. Residents were presented a list of adjectives and asked "please identify any word that describes how you feel about the overall format of the web-based exercise." Residents could select any adjective and were not limited to the number of responses.

teaching tool (6), an enjoyable experience (3), and a valuable adjunct to caring for homebound patients (2). Overall, written responses substantiated survey results with such comments as "I like the convenience of this type of encounter, but inability to perform physical exam is a huge disadvantage," "Regarding communication, the web-based exercise was effective. In a true clinical scenario, it is still inferior to face-to-face," and "there is nothing like face-to-face."

In addition, each of the 59 residents completed an adjective checklist and results can be found in Fig. 2.

As can be seen from the adjective checklist results, over $40 \%$ considered the format to be "practical," over 50\% described the format as "useful" or "informative," and almost $60 \%$ described the format as "interesting." No respondent described the format as "worthless."

Although the primary purpose of this study focused on residents' acceptance of and comfort using this formative assessment, descriptive statistics of performance were calculated as well (Table 3 ).

Table 3

Descriptive statistics of performance, overall by case $(n=59)$.

\begin{tabular}{lcccc}
\hline Descriptive statistic & Case 101 & Case 102 & Case 103 & Case 104 \\
\hline Global assessment ${ }^{\mathrm{a}}$ & & & & \\
Median & 3.625 & 3.125 & 3.250 & 3.125 \\
Min & 2.125 & 1.25 & 2.25 & 1.875 \\
Max & 4.0 & 3.875 & 4.0 & 4.0 \\
Self-assessment & & & & \\
Median & & & & \\
Min & 3.25 & 3.00 & 3.125 & 3.00 \\
Max & 2.5 & 2.5 & 2.125 & 2.286 \\
& 4.0 & 4.0 & 4.0 & 4.0 \\
Checklist & & & & \\
Median & & & & \\
Min & 91.67 & 75.00 & 75.00 & 64.29 \\
Max & 42.86 & 33.3 & 41.67 & 35.71 \\
ba & 100 & 100 & 100 & 100
\end{tabular}

a Global and self-assessments. Each of the eight global assessment measures was scored using a four-point Likert-type scale: needs much improvement (1), needs some improvement (2), done adequately (3), and done excellently (4). Descriptive statistics represent performance scores across each case for all resident participants.

b Checklist scores. Checklists (with elements identified as done or not done) were derived from input by the Case Development Committee by expert census; checklist items varied between 12 and 14 items for each case. Descriptive statistics represent performance scores, as a percent metric, across each case for all resident participants.

\section{Discussion and conclusion}

\subsection{Discussion}

Survey responses indicated the majority of resident participants valued the remote learning exercise, authenticity, ease of use, and educational opportunity. The web-based nature allows educators to reach learners at remote locations with limited exposure and opportunity. Synchronous learning and teleconferencing is becoming more common in medical education with comparable educational outcomes between remote and face-toface activities $[8,13,14]$. Unlike most previous research addressing synchronous pedagogical principles, this study addressed authenticity of clinical encounters with RSPs and interactive communication tasks. Novack et al. [9] found medical students who participated in a web-based clinical skills assessment reported high satisfaction but noted frustrations in their inability to touch patients and interpret non-verbal behaviors. This is particularly relevant for osteopathic physicians, who are trained to incorporate touch in the care of patients. Although 93\% of residents in this study acknowledged they could communicate easily with the RSPs, $80 \%$ preferred traditional face-to-face clinical experiences. Written comments such as "...there is nothing like meeting someone in person and being able to shake their hand," seem to substantiate the desire to incorporate touch in the training exercises. Responses and comments support the incorporation of web-based synchronous learning with RSPs, but such exercises should not replace face-to-face clinical education.

With the incorporation of technologies, challenges are inevitable. Previous research with WebOSCEs identified students' frustrations with technology and inability to interact with the computer environment [9]. Technology challenges were identified in this study as well. Even though $98 \%$ agreed or strongly agreed with the statement "I found Skype easy to use," $58 \%$ reported technical difficulties during the encounters. Written responses indicated challenges with dropped calls, as well as poor video and audio quality. As a result, residents reported inability to visualize subtle expressions, maintain comfortable communication flow, or convey empathy. A number of steps were taken to minimize technology-related complications: utilizing a commonly used videoconferencing program (Skype), developing and disseminating a comprehensive technology instruction document, and providing live technology support before and during the exercise. Perhaps other proprietary videoconferencing software would offer improved quality and reliability. Replicating the study with other technologies and programs would be worth considering for future research.

The topic of pain was selected because of the increased awareness of physicians' inability to manage pain appropriately, particularly in context of evaluating patients' pain and prescribing opioid medications for non-cancer pain [10]. The assessment and treatment of pain is complex and requires significant training. Physicians learn to rely on important verbal and nonverbal cues when communicating and examining patients. Communicating through the use of a web-based medium is likely to reduce the intensity of both verbal and nonverbal communication cues when compared to face-to-face encounters. As a training exercise, this reduction in fidelity may be acceptable. In this study, only $80 \%$ of residents agreed or strongly agreed to the statement "I feel more confident in my ability to communicate with my patients with regard to pain." Perhaps this is because residents feel they are already competent to manage pain, or perhaps this is because they feel pain assessment requires face-to-face interaction. As described by one resident, "it is difficult to assess pain without a physical examination," and perhaps, because of this limitation, the educational exercise provided limited value with regard to pain management. Topics other than pain may be considered for future 
web-based OSCEs, such as lifestyle modification, end of life discussions, medication compliance, anticipatory guidance, or depression.

Findings from this web-based OSCE experience seem to share similarities and differences with research pertaining to videoconferencing and telemedicine. Videoconference, although helpful in reaching learners at remote locations, has been shown to constrain dialog [15-17]. While 93\% of residents in this study agreed or strongly agreed that "I was able to communicate easily with the RSPs," a number of comments suggested a face-to-face encounter is preferred and would facilitate communication. Like videoconferencing, remote communication may constrain dialog; unlike videoconferencing, the one-on-one interactive communication as an OSCE may improve participant satisfaction with the communication task.

Although this web-based OSCE was designed for teaching purposes, a few resident responses alluded to telemedicine in their comments regarding the study. As an illustration, one resident reported "this could become a valuable alternative to home bound patients with minor complaints or counseling needs in the future." Our findings are similar to those found by others who researched communication in context of patient care through the use of telemedicine. Overall, patients and providers were satisfied with the quality of the telemedicine experience [18,19]; however, human factors impacting doctor-patient communication require further investigation [20,21]. Potential concerns include depersonalization, sensory and non-verbal limitations, third party participation, and social and professional distancing [22]. In addition, researchers have investigated human factors with regard to web-conferencing in industry and education. For instance, educational research has elucidated advantages with webconferencing such as improved flexibility and portability; however, identified challenges include frustrations with technology and inability to engage participants in a virtual classroom [23]. Like these issues raised by telemedicine and education researchers, doctor-patient communication and interaction require further investigation with web-based OSCEs.

There were a few limitations with the study. First, the sample included a small number of resident-level osteopathic physicians. Therefore, results may not be generalizable or applicable to other resident physicians or physicians in active practice. Second, a formal qualitative analysis, through the use of focus groups for instance, would assist in substantiating and clarifying survey responses. Third, because participation in the study was voluntary, there was likely a selection bias favoring residents who may be open to exploring novel assessments and new technology. Fourth, performance scores (checklist and global communication assessments) were not investigated in this study because the program was designed as a formative assessment and inter-rater reliability was unavailable (double scoring was not performed). Therefore, performance scores could not be correlated with other pre- or post-exercise assessments such as a clinical skills examination required for licensure. Fifth, comparisons between subgroups (e.g., pediatric versus emergency medicine residents) were not performed, given the small sample size within each of the demographic subcategories. Sixth, RSPs in this study were all experienced SPs with important insights to share regarding their experience, and their perspectives were not analyzed in this study. Further investigation is warranted to address these limitations.

\subsection{Conclusion}

Despite the interest in teaching and assessing communication skills among physicians, little research has focused on web-based OSCEs and RSPs. This is the first study to investigate the use of web-based OSCEs directed specifically at communication skills for residents across training sites, to solicit feedback specifically from osteopathic physicians, and to investigate the use of Skype as a cost-effective and ubiquitous communication tool. This study supports the continued investigation of web-based OSCEs as a formative assessment for doctor-patient communication, enhancing educational opportunities for residents and practicing physicians that is relevant, practical, and authentic. Preliminary results are encouraging and technology is advancing to improve quality, but future work is required to investigate the human factors which influence the communication quality and authenticity. Web-based OSCEs and RSPs offer a promising adjunct to teaching doctor-patient communication, but as stated by one of the residents of this study, "there is nothing like meeting someone in person and being able to shake their hand."

\subsection{Practice implications}

Doctor-patient communication is important to learn and develop throughout the career of a physician. This web-based OSCE is authentic, relevant and practical, making it a valuable adjunct for teaching and reinforcing doctor-patient communication skills for medical students, residents and practicing physicians. Such educational programs are valuable and practical, but unlikely to replace face-to-face encounters with patients.

\section{Acknowledgements}

We wish to thank each of the resident participants for volunteering, the RSPs for their dedication and enthusiasm to explore new assessments, the NBOME committee members for developing case content and clinical assessments, and Andrea Cannizzaro (NBOME) for her support with scheduling encounters and for her critical review of the manuscript.

\section{References}

[1] Accreditation Council on Graduate Medical Education. Common program requirements: general competencies, 2007. Retrieved from http://www.acgme.org/Outcome/comp/GeneralCompetenciesStandards21307.pdf [archived 8 June 2011 at http://www.webcitation.org/5zIFGOLtn].

[2] American Osteopathic Association. Core Competency Compliance Program (CCCP) Part III, 2004. Retrieved from http://www.do-online.org/pdf/ acc_cccppart3.pdf [archived 16 May 2012 at http://www.webcitation.org/ 67i2YR4Sg].

[3] Teutsch C. Patient-doctor communication skills. Med Clin North Am 2003;87:1115-45.

[4] Duffy FD, Gordon GH, Whelan G, Cole-Kelly K, Frankel R. Assessing competence in communication and interpersonal skills: the Kalamazoo II report. Acad Med 2004;79:495-507.

[5] Boulet JR, Smee SM, Dillon GF, Gimpel JR. The use of standardized patient assessments for certification and licensure decisions. Simul Healthc 2009;4:35-42.

[6] Holt KD, Miller RS, Nasca TJ. Residency programs' evaluations of the competencies: data provided to the ACGME about types of assessments used by programs. J Grad Med Educ 2010;2:649-55.

[7] Spagnoletti CL, Bui T, Fisher GS, Gonzaga AMR, Rubio DM, Arnold RM. Implementation and evaluation of a web-based communication skills learning tool for training internal medicine interns in patient-doctor communication. J Commun Healthc 2009;2:159-72.

[8] Daetwyler CJ, Cohen DG, Gracely E, Novack DH. eLearning to enhance physician patient communication: a pilot test of doc.com and WebEncounter in teaching bad news delivery. Med Teach 2010;32:e381-90.

[9] Novack DH, Cohen D, Peitzman SJ, Beadenkopf S, Gracely E, Morris J. A pilot test of WebOSCE: a system for assessing trainees' clinical skills via teleconference, Med Teach 2002:24:483-7.

[10] Fishman SM. Responsible opiod prescribing: a clinician's guide. DC: Waterford Life Sciences: Washington; 2012.

[11] Joyce BL, Steenbergh T, Scher E. Use of the Kalamazoo essential elements communication checklist (adapted) in an institutional interpersonal and communication skills curriculum. J Grad Med Educ 2010;2:165-9.

[12] Thomas SJ. Designing surveys that work: a step-by-step guide. Thousand Oaks, CA: Corwin Press; 1999

[13] Hortos K, Sefcik D, Wilson SG, McDaniel JT, Zemper E. Synchronous videoconferencing: impact on achievement of medical students. Teach Learn Med 2013;25:211-5. 
[14] Turner MK, Simon SR, Facemyer KC, Newhall LM, Veach TL. Web-based learning versus standardized patients for teaching clinical diagnosis: a randomized, controlled, crossover trial. Teach Learn Med 2006;18:208-14.

[15] Locatis C, Berner ES, Hammack G, Smith S, Maisiak R, Ackerman M. An exploratory study of co-location as a factor in synchronous, collaborative medical informatics distance education. BMC Res Notes 2010;3:30.

[16] Tu C, McIsaac M. The relationship between social presence and interaction in online classes. Am J Dist Educ 2002;16:131-50.

[17] Kelsey K. Participant interaction in a course delivered by interactive compressed video technology. Am J Dist Educ 2000;14:63-73.

[18] Oliver DP, Demiris G. Comparing face-to-face and telehealth-mediated delivery of a psychoeducational intervention: a case comparison study in hospice. Telemed J E Health 2010;16:751-3.
[19] Leggett P, Graham L, Steele K, Gilliland A, Stevenson M, O'Reilly D, et al. Telerheumatology-diagnostic accuracy and acceptability to patient, specialist, and general practitioner. Br J Gen Pract 2001;51:746-8.

[20] Demiris G, Charness N, Krupinski E, Ben-Arieh D, Washington K, Wu J, et al. The role of human factors in telehealth. Telemed J E Health 2010;16: 446-53.

[21] Miller EA. Telemedicine and doctor-patient communication: an analytical survey of the literature. J Telemed Telecare 2001;7:1-17.

[22] Miller EA. The technical and interpersonal aspects of telemedicine: effects on doctor-patient communication. J Telemed Telecare 2003;9:1-7.

[23] Cornelius S. Convenience and community? An exploratory investigation into learners' experiences of web conferencing. J Interact Learn Res 2013;24: 267-83. 